\title{
Circulating Fibrocytes Define a New Leukocyte Subpopulation That Mediates Tissue Repair
}

\author{
Richard Bucala, Lori A. Spiegel, Jason Chesney, \\ Margaret Hogan, and Anthony Cerami \\ The Picower Institute for Medical Research, Manhasset, New York, \\ U.S.A.
}

\begin{abstract}
Background: The host response to tissue injury requires a complex interplay of diverse cellular, humoral, and connective tissue elements. Fibroblasts participate in this process by proliferating within injured sites and contributing to scar formation and the longterm remodeling of damaged tissue. Fibroblasts present in areas of tissue injury generally have been regarded to arise by recruitment from surrounding connective tissue; however this may not be the only source of these cells.

Materials and Methods: Long-term culture of adherent, human, and murine leukocyte subpopulations was combined with a variety of immunofluorescence and functional analyses to identify a blood-borne cell type with fibroblast-like properties.
\end{abstract}

\begin{abstract}
Results: We describe for the first time a population of circulating cells with fibroblast properties that specifically enter sites of tissue injury. This novel cell type, termed a "fibrocyte," was characterized by its distinctive phenotype (collagen ${ }^{+} /$vimentin $^{+} / \mathrm{CD} 34^{+}$), by its rapid entry from blood into subcutaneously implanted wound chambers, and by its presence in connective tissue scars.

Conclusions: Blood-borne fibrocytes contribute to scar formation and may play an important role both in normal wound repair and in pathological fibrotic responses.
\end{abstract}

\section{INTRODUCTION}

Wounds result from an abrupt, physical disruption of the normal architecture of tissue and may be produced by trauma, burns, inflammatory processes, or metabolic insufficiency. Once wounding occurs, the host initiates a coordinated repair response that prevents infection and tissue invasion and ultimately reestablishes normal tissue integrity. This response occurs over several phases and involves a complex interplay between cellular, humoral, and connective tissue elements (1).

Connective tissue fibroblasts participate in the reparative phase of wound healing by producing matrix proteins, such as collagen, and forming a connective tissue scar. Over the long term, fibroblasts also act to remodel injured tis-

Address correspondence and reprint requests to: Richard Bucala, The Picower Institute for Medical Research 350 Community Drive, Manhasset, NY 11030, U.S.A. sue, maintain tissue homeostasis, and ensure the long-term survival of connective tissue. Fibroblasts that enter and proliferate within wound sites generally have been regarded to arise from the recruitment and migration of cells from adjacent tissue. Under normal circumstances, these cells are quiescent and remain sparsely distributed throughout the extracellular matrix $(2,3)$.

A frequently employed model for the study of wound healing responses relies on the surgical implantation of wound chambers that consist of short lengths of sponge-filled, silastic tubing (4). Implantation of these chambers into the subcutaneous tissues of mice results within $24 \mathrm{hr}$ in a rapid influx of peripheral blood cells comprising neutrophil, monocyte, and lymphocyte subpopulations $(4,5)$. While studying acute cellular responses in this model of wound repair, we observed by light microscopy an unexpectedly large number of adherent, spindle-shaped cells that resembled fibroblasts. The appearance of fi- 
broblasts in wound chambers has been attributed to their recruitment from surrounding subcutaneous tissue (1-3). Therefore, the presence of large numbers of fibroblast-like cells coincidentally with the entry of circulating inflammatory cells suggested to us that this cell population was arising from peripheral blood and not exclusively by slow migration from adjacent connective tissue. We describe herein the isolation and cell surface phenotype of this apparently novel, blood-borne, fibroblast-like cell. This cell type, which we have termed a fibrocyte, was found to enter sites of tissue injury and to contribute to connective tissue scar formation.

\section{MATERIALS AND METHODS}

\section{Isolation and Characterization of Blood-Borne Fibrocytes}

Total peripheral blood leukocytes were first isolated from human blood $(60 \mathrm{ml})$ by centrifugation over Ficoll-Paque following the manufacturer's protocol (Pharmacia). After overnight culture on $150 \mathrm{~mm}$ plates in Dulbecco's modified Eagle's medium (DMEM) supplemented with $20 \%$ fetal calf serum (FCS), nonadherent cells were removed by a single, gentle aspiration. At weekly intervals thereafter, the cultures were replenished with fresh medium. Morphological studies were performed after 6 weeks of culture on cells judged to be phenotypically homogenous by "spot" immunofluorescence and by flow cytometry with selected antigen markers (described below). Mouse cells were cultured in a similar manner from whole blood pooled from 5-10 individual mice.

\section{Immunofluorescence and FACS Analysis}

For cell surface analysis, cells were subcultured on cover slips prior to fixation with $3.5 \%$ paraformaldehyde for "spot" immunofluorescence analysis. Fixed cells were washed in a graded ethanol series at $-20^{\circ} \mathrm{C}$ followed by three washes in phosphate buffered saline (PBS). Cover slips then were incubated for $30 \mathrm{~min}$ at room temperature with $10 \mu \mathrm{g} / \mathrm{ml}$ of monoclonal antibodies. For enumeration studies, anti-collagen I, anti-vimentin, and anti-CD34 monoclonal antibodies were used. FITC-linked anti-mouse IgG was used as a secondary antibody. For fluorescence-activated cell sorting (FACS), cells were harvested after 6 weeks of culture by gentle scraping and trituration and either incubated directly with specific antibodies or first permeabilized and fixed with $3.5 \%$ paraformaldehyde (6). At least 10,000 cells were analyzed on an FACS 440 (Becton Dickinson) instrument. The sources of the antibodies that were tested against mouse antigens included: anti-fibronectin and anti-collagen I (Chemicon), antiMacI and anti-PanMac (Serotec), anti-CD4, antiCD8, anti-TCR $(\alpha \beta)$, anti-TCR $(\gamma \delta)$, anti-CD l la, anti-CD25, anti-CD45, anti-CD54, anti-LPAM, and anti-LECAM-1 (each from Pharmingen). Antibodies to human antigens included: anti-von Willebrand's antigen (Accurate), anti-vimentin (Labsystems), anti-collagen I and anti-collagen III (Chemicon), anti-laminin, anti- $\alpha$-actin, antifibronectin, and anti-desmin (Sigma, St. Louis, MO, U.S.A.), anti-Class I, anti-Class II, anti-CD3, anti-CD4, anti-CD8, anti-TCR $(\alpha \beta)$, anti-TCR $(\gamma \delta)$, anti-CD 1 la, anti-CD1 lb, anti-CD11c, anti-CD13, anti-CD14, anti-CD16, anti-CD19, anti-CD25, anti-CD33, anti-CD34, anti-CD38, anti-CD44, anti-CD45, anti-CD54, anti-CD56, and antiCD71 (each from Boehringer Mannheim).

\section{Electron Microscopy Analysis}

Scanning and transmission electron microscopy studies were kindly performed by Dr. David Phillips (The Population Council, New York). For scanning electron microscopy, cells were fixed in PBS $/ 2.5 \%$ glutaraldehyde, dehydrated in a graded ethanol series, critical point dried from liquid $\mathrm{CO}_{2}$, and viewed in an ETEC scanning electron microscope.

\section{Wound Chamber and Scar Tissue Studies}

Female BALB/c mice (4-6 weeks old) were anesthetized with Avertin. Sterile wound chambers composed of a $2.5 \mathrm{~cm}$ piece of perforated silastic tubing (Dow Corning) containing polyvinylalcohol sponge (Unipoint, Inc.) were inserted through a $0.5 \mathrm{~cm}$ dorsal midline incision along each flank (4). At intervals, 10-20 $\mu \mathrm{l}$ of wound fluid was aspirated percutaneously with a $1 \mathrm{cc}$ syringe, and the cells were recovered by centrifugation. After washing in PBS, cells were analyzed by flow cytometry for total cell count and reactivity with directly labeled anti-CD34, anticollagen I, and anti-vimentin monoclonal antibodies. In selected experiments, wound chambers were removed at intervals $(7,14,28$, and 56 days), fixed in $3.5 \%$ paraformaldehyde, sectioned, and stained with hematoxylin/eosin, 
Masson-Trichrome (for collagen), or processed for immunohistochemistry.

Scar tissue formation was induced in selected mice by a $0.5 \mathrm{~cm}$ dorsal midline scalpel incision that was then closed with a surgical staple. The area encompassing cutaneous scar was excised 7-28 days later and processed for immunohistochemical analyses. After blocking endogenous peroxidases with $\mathrm{H}_{2} \mathrm{O}_{2}(3 \%)$, sections were stained with a monoclonal rat antibody to mouse CD34 (1:100 dilution) or a rat IgG1 isotypic control and developed with an immunoperoxidaselinked secondary antibody (DAKO, Copenhagen, Denmark) using diaminobenzidene as substrate.

Human cutaneous scar tissue specimens were kindly provided by Dr. Joseph Ma (Department of Pathology, Albany Medical College, NY, U.S.A.). These specimens were obtained from individuals without any apparent systemic inflammatory or connective tissue diseases. Sectioned tissue was stained with hematoxylin and eosin and analyzed for CD34 expression as described above.

\section{Bone Marrow Chimera Studies}

Female $(B A L B / c)$ mice were lethally irradiated (800 rads) and reconstituted intravenously with $10^{6}$ bone marrow cells harvested from the femurs of male (BALB/c) mice (7). Wound chambers were implanted into mice 6 weeks after bone marrow transfer. At intervals, 10-20 $\mu$ l of fluid was aspirated from the chambers for cell analysis. Wound chamber cells were recovered by centrifugation, washed, fixed, and doublestained with rhodamine-conjugated monoclonal anti-CD34 and FITC-labeled monoclonal anticollagen I antibodies. Cells were subjected to fluorescence-activated cell sorting and two populations (CD34- $/$ Collagen $\mathrm{I}^{-}$and $\mathrm{CD} 34^{+} /$Collagen $\left.\mathrm{I}^{+}\right)$were recovered for DNA analysis. Thresholds were determined with FITC and rhodamine isotype controls.

DNA was prepared from approximately 10,000 sorted cells by lysis in Tris-buffer containing $0.1 \%$ SDS and $0.1 \mathrm{mg} / \mathrm{ml}$, proteinase $\mathrm{K}$ and used as a template in $50 \mu \mathrm{l} \mathrm{PCR}$ reactions containing $10 \mathrm{mM}$ Tris buffer, $\mathrm{pH} 8.3,50 \mathrm{mM} \mathrm{KCl}$, $1.5 \mathrm{mM} \mathrm{MgCl}, 0.001 \%$ gelatin, $0.2 \mathrm{mM}$ each of dATP, dCTP, dGTP, and dTTP, $1 \mu \mathrm{M}$ each of the oligonucleotide primers, and $0.026 \mathrm{U} / \mu \mathrm{l}$ of $\mathrm{Taq}$ polymerase. After an initial 2 min denaturation step, each amplification cycle consisted of $1 \mathrm{~min}$ of denaturation at $92^{\circ} \mathrm{C}, 1 \mathrm{~min}$ annealing at $53^{\circ} \mathrm{C}$, and $1 \mathrm{~min}$ polymerization at $72^{\circ} \mathrm{C}$. Sam- ples were amplified for 45 cycles. The primers for the Y chromosome-specific $S R Y$ gene $\left(5^{\prime}\right.$-AAGT TGGCCCAGCAGAAT-3' and 3'-TATAGTCGGAG TAGCCTC-5') (8) amplify a 143 bp genomic DNA fragment, and the $\beta$-actin primers (5'-GTGGG CCGCTCTAGGCACC-3' and 3'-CCCCCTGAACC CCTAAGGCCA-5') (9) amplify a 241 bp genomic DNA segment. Ten microliters of reaction products were analyzed by gel electrophoreses in $2 \%$ agarose gels containing $100 \mathrm{ng} / \mathrm{ml}$ of ethidium bromide.

\section{RESULTS}

In preliminary studies performed in mice, we observed that a large proportion of cells aspirated within 2 days of wound chamber implantation showed an adherent, spindle-shaped phenotype that was reminiscent of cultured primary fibroblasts. Further analyses demonstrated these cells to stain strongly for the fibroblast markers collagen I and vimentin and to be negative for nonspecific esterases, indicating that these cells were phenotypically distinct from the numerically larger copopulation of adherent, peripheral blood monocytes. We considered that any fibroblast-like cells present in circulation would be likely to comprise only a small fraction of peripheral blood cells and thus turned to an examination of human blood (available in greater quantities) for the identification of circulating fibroblast-like cell types.

Total leukocyte fractions were isolated from peripheral blood by Ficoll centrifugation and cultured in serum-supplemented DMEM under conditions selective for the ability of connective tissue cells to adhere to plastic surfaces and proliferate. As expected, there was a slow decline in the nonproliferating monocyte cell population over a 2-4 week period. This was accompanied by the emergence of expanding clusters of adherent cells that gradually increased in number. Light microscopy showed this proliferating cell type (henceforth termed a fibrocyte) to display a largely fibroblast-like, spindle-shaped morphology (Fig. la). Staining for nonspecific esterases was not observed, indicating that fibrocytes were not derived from monocyte/macrophages (data not shown). Furthermore, there was positive staining for the fibroblast cytoskeletal component vimentin and for collagen I $(10,11)$ (Fig. 1b). Scanning electron microscopy showed these cells to be morphologically distinct from circulating blood leukocytes and to display prominent 

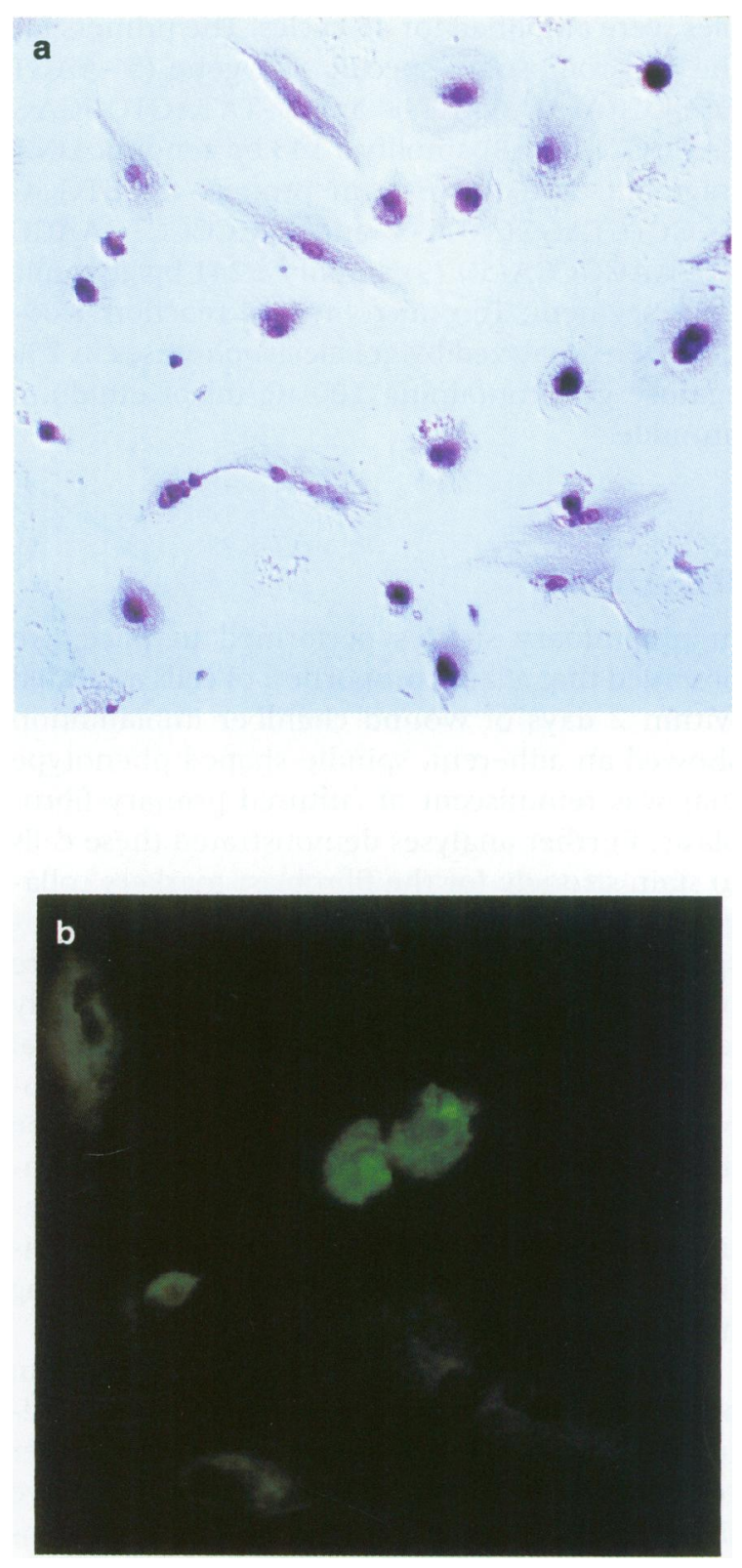

cell surface projections intermediate in size between microvilli and pseudopodia (Fig. 1c).

We then performed a systematic phenotypic characterization of fibrocytes by immunofluorescence staining. Human fibrocytes were markedly positive for the cytoskeletal component vimentin, the fibroblast products collagen I, collagen III, and fibronectin, and the adhesion molecules $\mathrm{CD} 1 \mathrm{lb}$ and $\mathrm{CD} 18$ (Fig. 2 and Table 1). Fibrocytes were found not to express a variety of epithelial, endothelial, or smooth muscle cell-specific markers. Fibrocytes did stain positively for a few typical, leukocyte-associated cell surface antigens, such as the leukocyte common antigen

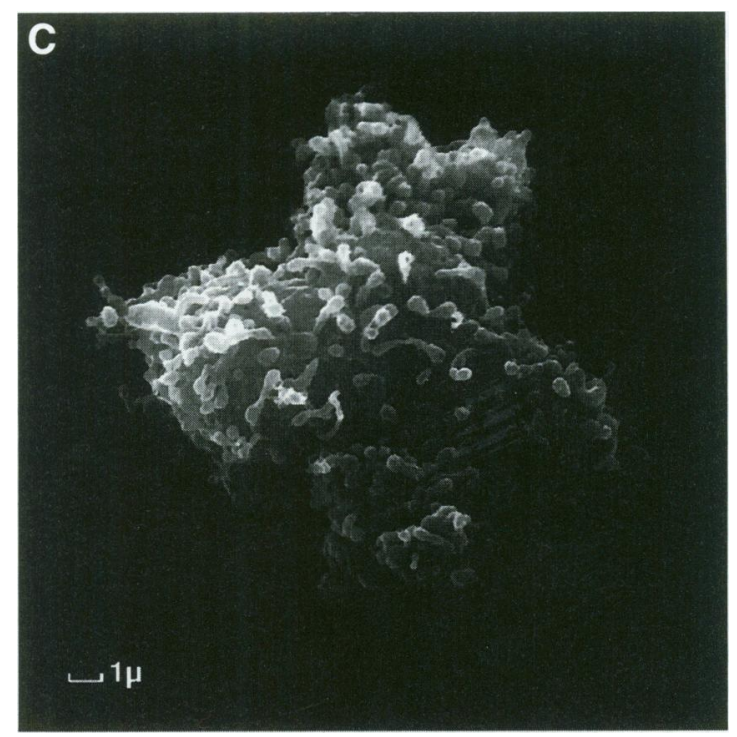

FIG. 1. Morphological appearance of fibrocytes isolated from cultures of human peripheral blood

(a) Light microscopic appearance after 6 weeks of culture $(340 \mathrm{X})$. (b) Immunofluorescence staining with monoclonal anti-vimentin antibody (640X). (c) Scanning electron micrograph.

CD45 and the hematopoietic stem cell antigen CD34 (13-15). The CD34 antigen was identified originally to be a marker of bone marrow progenitor cells but has been reported recently to be expressed also by capillary endothelium and by embryonic fibroblasts $(16,17)$. We hypothesized that the $\mathrm{CD}_{3} 4^{+}$, vimentin ${ }^{+}$, collagen $\mathrm{I}^{+}$fibrocytes isolated from peripheral blood represent a circulating population of uncommitted (or incompletely differentiated) fibroblast precursors that are conceivably of bone marrow origin.

Using immunofluorescence "spot" staining, we then examined the time-dependent appearance of $\mathrm{CD}_{3} 4^{+}$, collagen $\mathrm{I}^{+}$cells in cultures prepared from human peripheral blood (Fig. 3). In agreement with previous morphological analyses, the proportion of cells positive for collagen and CD34 increased slowly over time as fibrocytes divided and the monocyte population expired. Fibrocytes exhibited a doubling time of approximately 3-4 days (data not shown), and appreciable percentages of adherent fibrocytes were not apparent until $\geq 2$ weeks of culture. We also sought to verify the existence of similar blood-borne cells in the mouse. Blood was obtained by cardiac puncture from BALB/c mice, subjected to the same fractionation and culture 

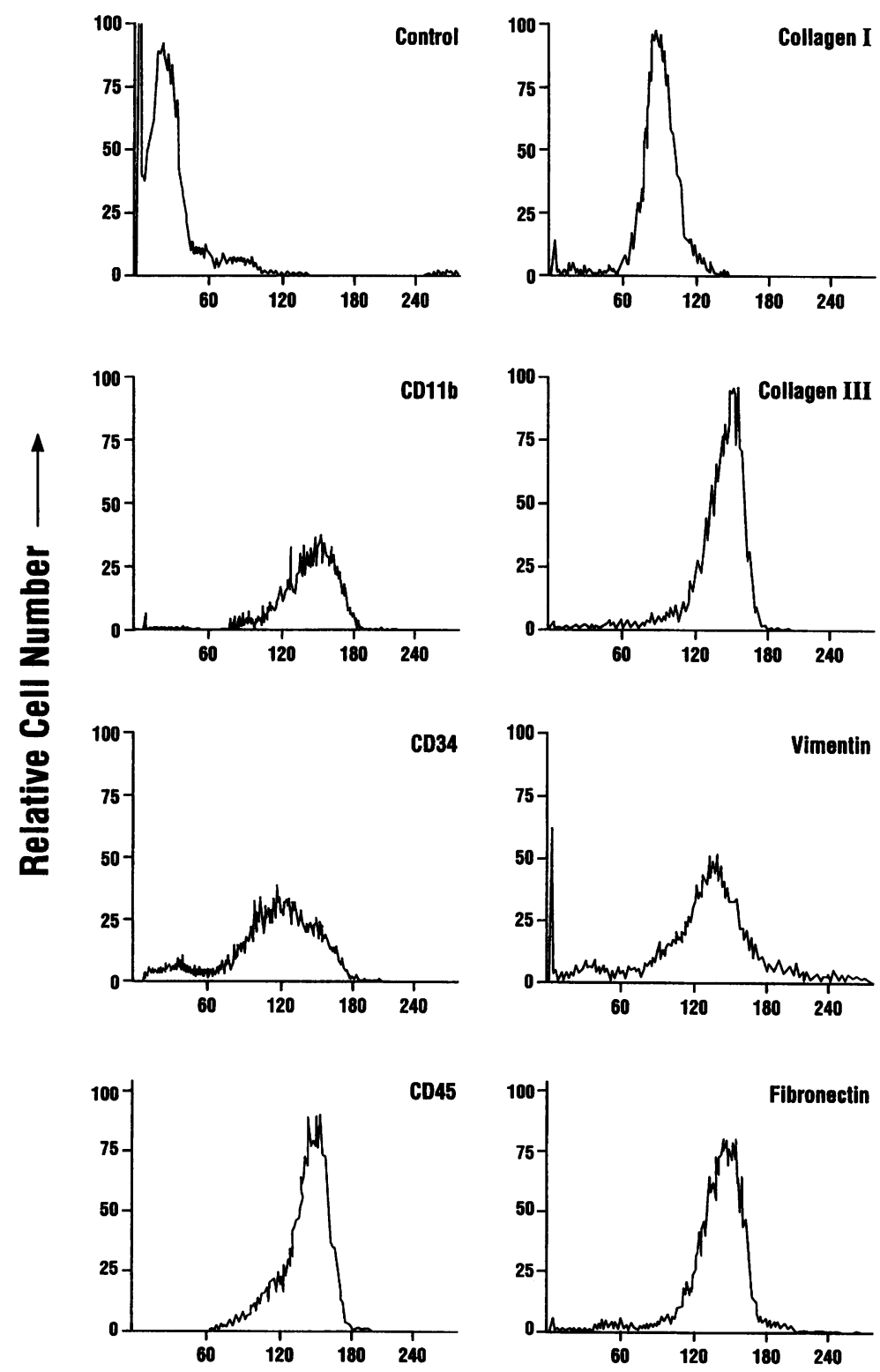

\section{Relative Fluorescence Intensity}

procedures as utilized for human blood, and found to yield cells with the same morphological properties as human fibrocytes. Immunofluorescence analysis with available mouse cell surface markers confirmed the existence of a fibrocyte cell population in mouse peripheral blood (collagen $\mathrm{I}^{+}$, vimentin ${ }^{+}$, fibronectin ${ }^{+}, \mathrm{CD}_{11 \mathrm{~b}}{ }^{+}$, $\mathrm{CD}_{18}{ }^{+}, \mathrm{CD}_{4} 4^{+}, \mathrm{CD}_{4} 5^{+}$, esterase ${ }^{-}, \mathrm{CD} 14^{-}$, $\mathrm{CD} 25^{-}$, and $\mathrm{CD} 54^{-}$) (data not shown).

Wound chambers were then implanted in mice, and cells were collected from the exudative fluid for analysis by microscopy and cytofluorimetry. As expected, the implantation of wound chambers in mice resulted in a rapid infiltration of acute inflammatory cells (i.e., neutrophils and monocytes), which reached a concentration of $1.3-1.5 \times 10^{6}$ cells $/ \mathrm{ml}$ (Fig. 4). Double immunofluorescence analysis showed that over 10 days, $10-15 \%$ of the cells present in wound chamber fluid stain positively for both collagen I (or vimentin) and CD34, indicating that a population of blood-borne cells with the same phenotypic features as cultured fibrocytes infiltrate wound chambers as part of the acute, inflammatory reaction. Over time, these $\mathrm{CD} 34^{+} /$collagen $\mathrm{I}^{+}$cells were found to adhere to the polyvinylalcohol 
TABLE 1. Cell surface phenotype of human peripheral blood fibrocytes (subpopulation reactivity compiled from (12))

\begin{tabular}{|c|c|c|}
\hline Antigen & & Cell Subpopulations \\
\hline \multicolumn{3}{|c|}{ Positive Expression } \\
\hline Vimentin & Intermediate filament & Fibrobasts \\
\hline Fibronectin & Pericellular Matrix & Mesenchymal cells, lymphoid cells \\
\hline Collagen I & Extracellular matrix & Fibroblasts \\
\hline Collagen III & Extracellular matrix & Fibroblasts \\
\hline CDllb & Adhesion molecule & Monocytes, granulocytes, NK cells \\
\hline $\mathrm{CD} 13$ & Aminopeptidase $\mathrm{N}$ & Myeloid and dendritic cells \\
\hline CD18 & Integrin $\beta 2$ & Lymphoid and myeloid cells \\
\hline CD34 & Precursor antigen & Hematopoietic progenitors, embryonic fibroblasts \\
\hline CD45 & Leukocytes Common Antigen & Leukocytes \\
\hline CD71 & Transferrin receptor & Macrophages, activated cells \\
\hline \multicolumn{3}{|c|}{ Negative Expression } \\
\hline Esterase & Lysosomal enzyme & Monocytes and granulocytes \\
\hline $\operatorname{TCR}(\alpha \beta, \gamma \delta)$ & Antigen receptor & T-Cells \\
\hline Cytokeratin & Matrix protein & Epithelial cells \\
\hline von Willebrand & Coagulation factor & Endothelial cells and platelets \\
\hline Desmin & Intermediate filament & Muscle cells \\
\hline$\alpha$-Actin & Cytoskeletal protein & Smooth muscle cells \\
\hline Laminin & Matrix protein & Blood vessels, muscle cells, nerve, etc. \\
\hline CD3 & TCR-associated antigen & T-Cells \\
\hline CD4 & Class II recognition & Helper/inducer T-cells \\
\hline CD8 & Class I recognition & Cytotoxic/suppressor T-cells \\
\hline CD 10 & Endopeptidase (CALLA) & B-cell subpopulations \\
\hline CDlla & LFA-1 antigen & Lymphoid and myeloid cells \\
\hline CDl4 & LBP receptor & Monocytes/macrophages \\
\hline CD 16 & Fc $\gamma$ RIII (Ig receptor) & Monocytes, granulocytes, NK cells \\
\hline CD19 & B-cell antigen & B-cells \\
\hline CD25 & IL-2 receptor & Activated macrophages/T-/B-cells \\
\hline CD33 & Pan-myeloid antigen & Myeloid and monocytic cells \\
\hline CD38 & $\mathrm{T} 10$ antigen & Precursor cells, activated T-/B-cells \\
\hline CD44 & Lymphocytes homing receptor & Leukocytes and erythrocytes \\
\hline CD54 & ICAM-1 & Monocytes and lymphocytes \\
\hline CD56 & NCAM & NK and T-cell subpopulations \\
\hline
\end{tabular}

sponge material present in wound chambers and to proliferate within regions of scar formation (described below).

The presence on fibrocytes of the hematopoietic stem cell antigen CD34 led us to investigate more closely the possible bone marrow origin of these cells. To test for the possibility that circulating fibrocytes might arise from hematopoietic progenitors, we utilized sex-mismatched bone marrow chimeric mice together with DNA amplification of the male-specific SRY gene to detect cells arising from transplanted (male) bone marrow cells $(8)$. Wound chambers were implanted in mice 6 weeks after the transfer of male bone marrow cells to lethally irradiated, female hosts. At intervals thereafter, wound fluid was aspi- 


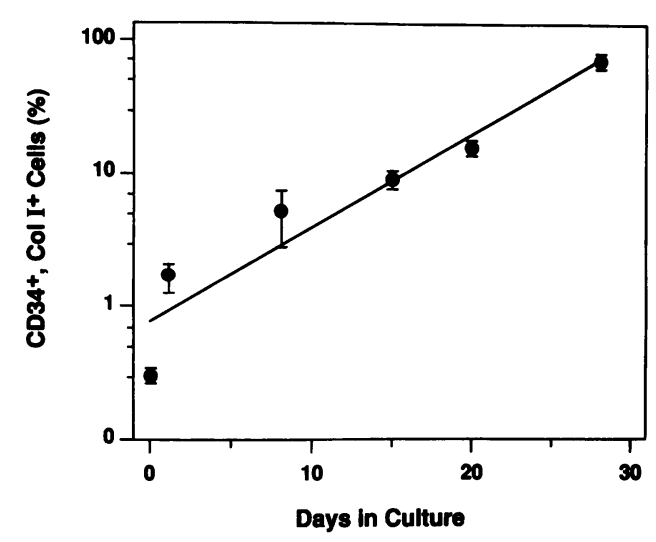

FIG. 3. Time-dependent appearance of fibrocytes in cultures of adherent, human peripheral blood leukocytes

Peripheral blood leukocyte fractions were isolated as described in Materials and Methods, cultured on glass cover slips, fixed, and double-stained with rhodamine-conjugated monoclonal anti-human CD34 antibody plus FITC-conjugated monoclonal antihuman collagen I antibodies. Similar results were obtained by double-staining with anti-CD34 plus monoclonal anti-vimentin antibodies. At least 10 positive cells were enumerated within each field (mean $\pm S E M$ of $\geq 3$ fields/time point).

rated, and the cells were separated by FACS into $\mathrm{CD} 34^{-} /$collagen $\mathrm{I}^{-}$and $\mathrm{CD} 34^{+} /$collagen $\mathrm{I}^{+}$populations. As expected, DNA isolated from the $\mathrm{CD}^{-} 4^{-} /$collagen $\mathrm{I}^{-}$population produced a significant amount of the SRY DNA amplification product, confirming the bone marrow (male) origin of the majority of the inflammatory cell population (Fig. 5). By contrast, DNA amplification analysis of $\mathrm{CD} 4^{+} /$collagen $\mathrm{I}^{+}$cells did not yield a significant amount of the $S R Y$-specific DNA product, arguing that this cell population did not arise from transferred (male) bone marrow. These results could not be attributed to either poor amplification efficiencies or to a low yield of DNA template since each cell population produced approximately equal amounts of the control, $\beta$-actin amplification product. Taken together, these data suggest that blood-borne fibrocytes do not originate from radiosensitive, hematopoietic stem cells but arise instead from either a radioresistant, bone marrow progenitor cell or from other tissue sources. Bone marrow stromal cells for example, are relatively radioresistant and may express the CD34 antigen $(17,18)$. Consistent with this possibility, we have detected persistent CD34 expression in bone marrow stroma after the irradiation and depletion of all hematopoietic cells (data not shown).

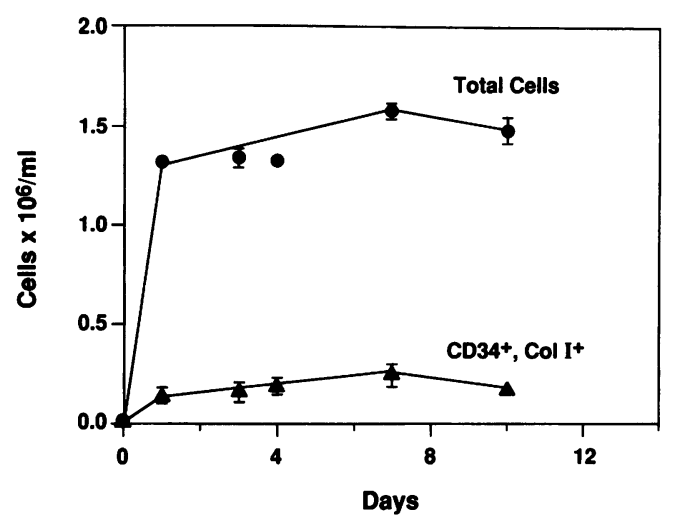

FIG. 4. Time-dependent appearance of fibrocytes in subcutaneously implanted wound chambers

Cellular analysis was performed on 5-10 $\mu$ l of fluid aspirated from wound chambers at the intervals shown. Cells were enumerated by cytofluorimetry and then double-stained with rhodamine-conjugated monoclonal anti-murine CD34 plus FITC-conjugated monoclonal antimurine collagen I. Similar results were obtained by double staining with anti-CD34 plus antivimentin antibodies. Each time point represents the mean \pm SEM of three or four independent fluid samplings.

To assess more directly the role of circulating fibrocytes in wound repair, we next examined scar tissue obtained from wound chambers that had been implanted in mice for a period of 7-56 days. The chambers were removed, examined histologically, and analyzed for reactivity with monoclonal anti-CD34 antibody or an isotypematched antibody control (Fig. 6a). CD $34^{+}$cells exhibiting fibroblast morphology were readily identified in areas of scarring and connective tissue cell proliferation. In addition, progressively more anti-CD34 staining (and fibrosis) was observed with increasing time after implantation. We then examined cutaneous, connective tissue scars obtained from mice for the presence of $\mathrm{CD} 34^{+}$expression. Skin was removed from mice 28 days after an experimentally induced, surgical incision and stained with monoclonal anti-CD34 antibody. As shown in Fig. 6b, areas of connective tissue scar and cellular proliferation were markedly positive for CD34.

Finally, we examined cutaneous scar tissue obtained from a human subject at autopsy. Positive staining for CD34 was observed within the subcutaneous regions of human scar but not in sections obtained from control, nonscarred skin (Figs. 7a-7e). 


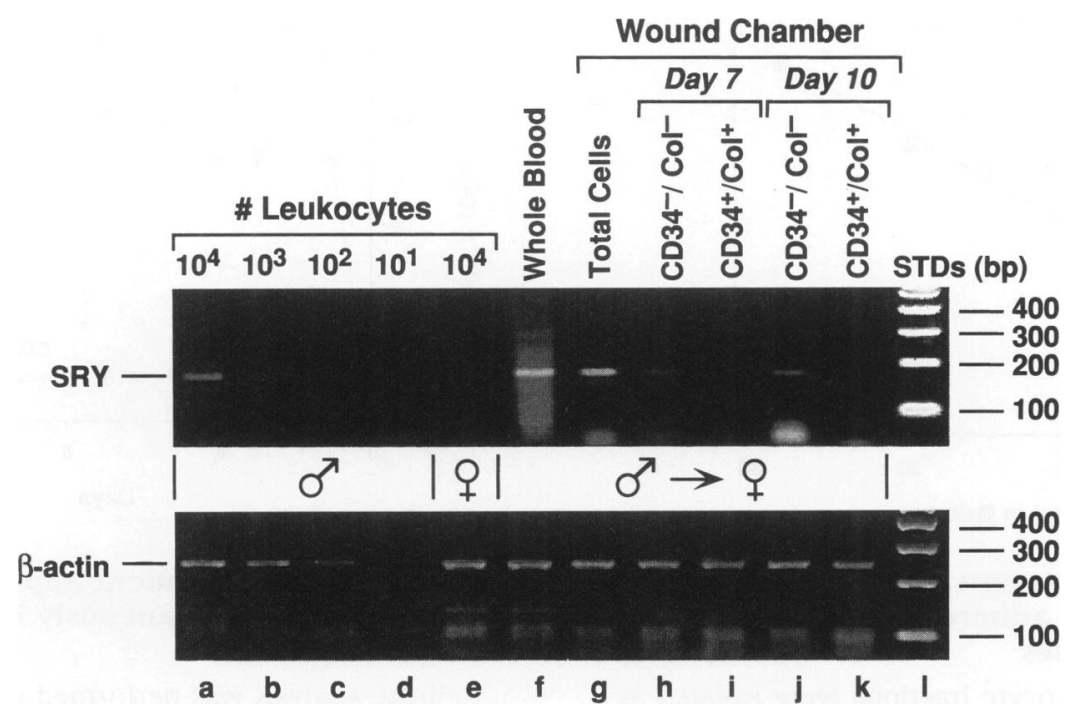

FIG. 5. DNA amplification analysis of wound chamber fibrocytes isolated from male $\rightarrow$ female bone marrow chimeric mice

One thousand leukocyte equivalents of whole blood (lane f) or wound chamber cells (lanes g-k) were obtained from female mice reconstituted 6 weeks previously with male bone marrow cells. For quantitative purposes (lanes a-e), genomic DNA was first prepared from defined numbers of peripheral blood leukocytes and amplified with primers specific for the Y chromosome SRY gene, or the $\beta$-actin gene as shown. Whole blood (104 leukocyte equivalents) from a representative bone marrow recipient (male $\rightarrow$ female) was amplified in lane f. Lane $g$ shows amplification products obtained from the DNA of $10^{4}$ total wound chamber cells before sorting. Lanes $h-k$ show amplification products obtained after sorting wound chamber cells into CD $34^{-} /$Collagen I$^{-}$(lanes $\mathrm{h}$ and $\mathrm{j}$ ) and $\mathrm{CD} 4^{+} /$Collagen $\mathrm{I}^{+}$populations (lanes $\mathrm{i}$ and $\left.\mathrm{k}\right)\left(10^{4}\right.$ cells per analysis). "Day 7" and "Day $10^{\prime \prime}$ refer to cells recovered at 7 or 10 days postwound chamber implantation. Results shown are representative of duplicate determinations performed in each of four mice.

\section{DISCUSSION}

These studies provide direct evidence for the participation of a novel, blood-borne fibroblast-like cell in the host repair response to tissue injury. This cell, which we have termed a fibrocyte, appears concurrently with circulating inflammatory cells and accounts for approximately $10 \%$ of the cells that infiltrate subcutaneously implanted wound chambers. Of significance, fibrocytes are found in regions of scar formation, both within wound chambers and in subcutaneous connective tissue. Cell surface analysis suggests that these cells share both leukocytic and connective tissue cell features. In addition to expressing the fibroblast components vimentin, collagen, and fibronectin, fibrocytes also display the leukocyte common antigen CD45 and the hematopoietic stem cell marker CD34. The CD34 antigen comprises a $110 \mathrm{kD}$ integral membrane glycoprotein that is present on myeloid and lymphoid progenitors (13-16), as well as on a stem cell population capable of reconstituting the bone marrow of lethally irradiated hosts (19). CD34 also has been shown to be expressed to varying degrees on capillary endothelium and embryonic fibroblasts $(16,17)$. However, the absence of staining for von Willebrand's antigen together with the distinctive cell surface phenotype of fibrocytes argues against their endothelial origin. The observation that fibrocytes isolated from wound chambers implanted into sex-mismatched bone marrow chimeras originate from the host also indicates that these cells arise either from radioresistant bone marrow stromal elements or from non-bone marrow sources of mesenchymal cell progenitors. Conceivably, fibrocytes that circulate in peripheral blood may comprise a population of pluripotent connective tissue cell precursors that can differentiate along either fibroblast, smooth muscle, or osteogenic lines depending on the precise microenvironment of various wound sites.

The observation that circulating, connective tissue cells contribute to the healing phase of wound repair complements long-standing observations that point to the critical role of vascular integrity in normal tissue repair responses $(3,20)$. Together with the infiltrating inflammatory cells 

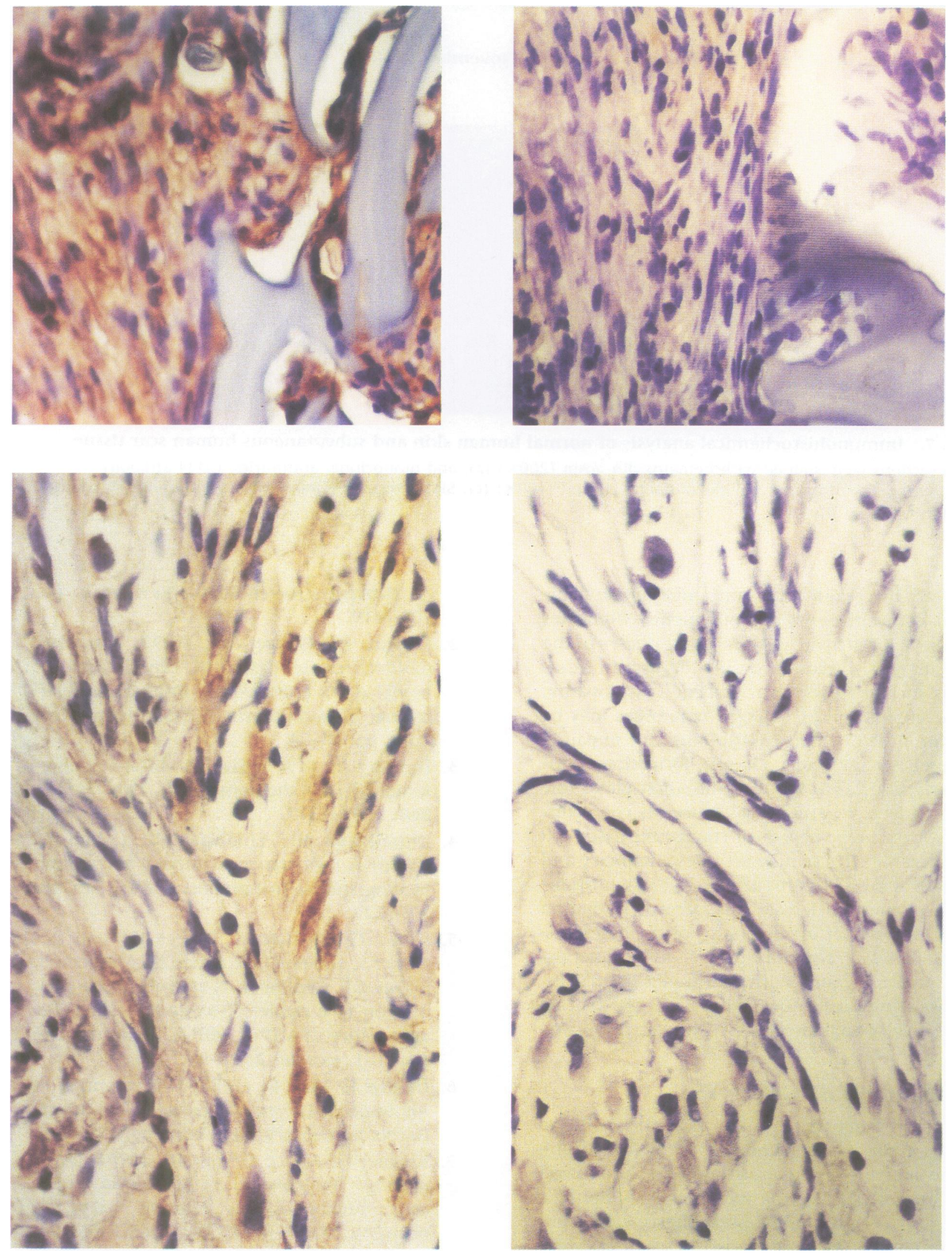

FIG. 6. Immunohistochemical analysis of murine fibrocytes in wound chambers and cutaneous scar tissue.

(a) Representative sections obtained from wound chambers 28 days after implantation in mice $(400 \times)$. Adjacent sections were stained with either monoclonal anti-murine CD34 (left) or with a isotypic antibody control (right) and developed with an immunoperoxidase-linked secondary antibody. The areas of homogenous blue staining are polyvinylalcohol sponge. Qualitatively similar results were obtained in wound chambers removed 7, 14, and 56 days after implantation. However, progressively more fibrosis (and anti-CD34 staining) was observed with increasing time after implantation. (b) Immunohistochemical analysis of a mouse cutaneous scar obtained 28 days after an experimentally induced cutaneous incision $(400 \times)$. Sections were stained as above with either monoclonal anti-murine CD34 (left) or with an isotypic antibody control (right) and developed with an immunoperoxidaselinked secondary antibody. Sections obtained from corresponding regions of control, nonscarred mouse skin showed no detectable staining with anti-CD34 antibody. 

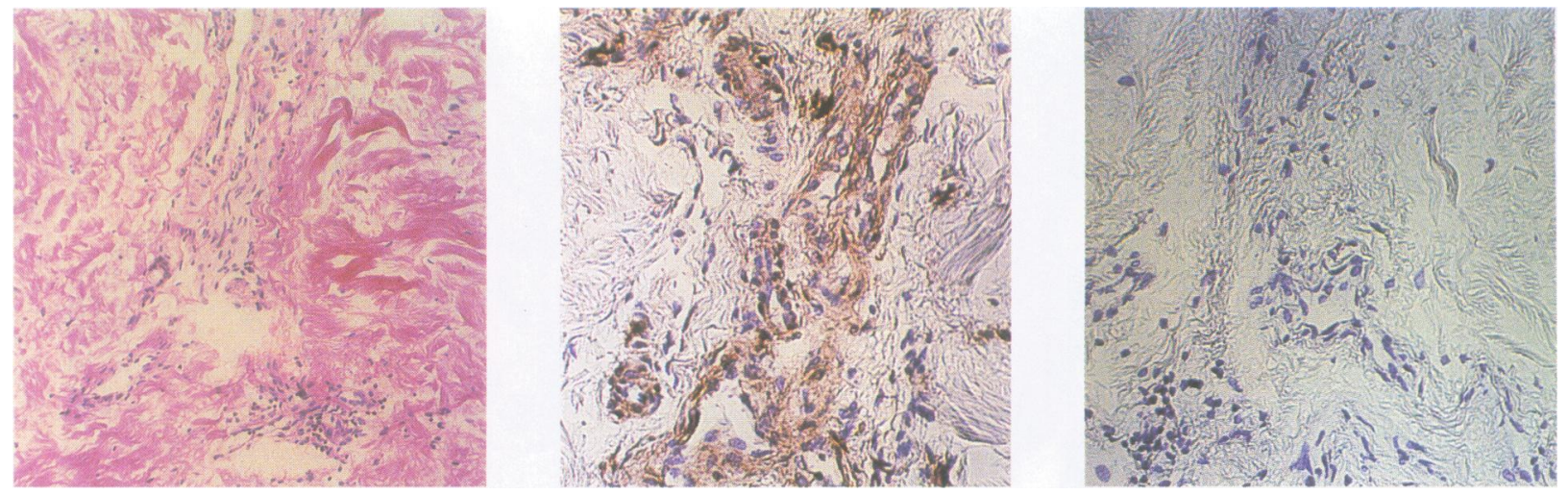

FIG. 7. Immunohistochemical analysis of normal human skin and subcutaneous human scar tissue

Skin sections were stained with hematoxylin-eosin $(200 \times)(a)$, and monoclonal antimurine CD34 antibody $(400 \times)(b)$, or with or an isotypic antibody control $(400 \times)$ (c). Slides were developed with an immunoperoxidaselinked secondary antibody.

that act to prevent infection and degrade damaged connective tissue components, fibrocytes appear to participate in the earliest phases of the physiological response to tissue injury. In situations such as ischemia or diabetic vasculopathy, fibrocyte entry into damaged tissue sites may be compromised, thus contributing to impaired wound healing and poor scar formation. Conversely, circulating fibrocytes also may play a role in a variety of pathological processes characterized by excessive fibrosis or connective tissue cell proliferation. These may include pulmonary and hepatic fibrosis, atherosclerosis and restenosis injury, glomerulosclerosis, and pannus formation (21-24). Further investigations of the differentiation pathway, secretory profile, and precise tissue origin of blood-borne fibrocytes should increase significantly our understanding of the role of this cell population in tissue repair responses.

\section{ACKNOWLEDGMENTS}

We thank Peter Gregersen for assistance with the FACS analyses, Tom Donnelly for help with the bone marrow chimera experiments, and David Phillips for the electron microscopy studies. We are also grateful to Barbara Sherry and John Eaton for helpful discussions. These studies were supported by a grant from the Arthritis Foundation and NIH \#RO1 AI-29110.

\section{REFERENCES}

1. Davidson JM. (1992) Wound repair. 2nd ed. In: Gallin JI, Goldstein IM, Snyderman R (eds). Inflammation: Basic Principles and Clini- cal Correlates. Raven Press, New York, pp. 809-819.

2. Morgan CJ, Pledger WJ. (1992) Fibroblast proliferation. In: Cohen IK, Diegelmann RF, Lindblad WJ (eds). Wound Healing: Biochemical and Clinical Aspects. WB Saunders, New York, pp. 63-76.

3. Dunphy JE. (1963) The fibroblast-A ubiquitous ally for the surgeon. N. Engl. J. Med. 268: 1367-1377.

4. Diegelmann RF, Lindblad WJ, Cohen IK (1986) A subcutaneous implant for wound healing studies in humans. J. Surg. Res. 40: 229-237.

5. Fahey TJ III, Shery B, Tracey KJ, van Deventer S, Jones WG II, Minei JP, Morgello S, Shires GT, Cerami A. (1990) Cytokine production in a model of wound healing: The appearance of MIP-1, MIP-2, cachectin/TNF and IL-1. Cytokine 2: 92-99.

6. Harlow E, Lane D. (1988) Cell staining. In: Antibodies, a Laboratory Manual. Cold Spring Harbor Laboratory, New York, pp. 359-420.

7. Brecher G, Lawce H, Tjio JH. (1991) Bone marrow transfusions in previously irradiated, hematologically normal syngeneic mice. Proc. Soc. Exp. Biol. Med. 166: 389-393.

8. Sinclair AH, Berta P, Palmer MS, Hawkins R, Griffiths BL, Smith MJ, Foster JW, Frischauf A, Lovell-Badge R, Goodfellow PN. (1990) A gene from the human sex-determining region encodes a protein with homology to a conserved DNA-binding motif. Nature 346: 240-244.

9. Alonso S, Minty A, Bourlet Y, Buckingham 
M. (1986) Comparison of three actin-coding sequences in the mouse: Evolutionary relationships between the actin genes of warmblooded vertebrates. J. Mol. Evol. 23: 11-22.

10. Franke WW, Schmid E, Winter S, Osborn M, Weber K. (1979) Widespread occurrence of inter-mediate-sized filaments of the vimentin-type in cultured cells from diverse vertebrates. Exp. Cell Res. 123: 25-46.

11. Virtanen I, Lehto VP, Lehtonen E, Vartio T, Stenman S, Kurki P, Wager O, Small JV, Dahl D, Badley RA. (1981) Expression of intermediate filaments in cultured cells. $J$. Cell Sci. 50: 45-63.

12. Coligan JE, Kruisbeek AM, Margulies, DH, Shevach EM, Strober W. (1992) The CD system of leukocyte cell surface molecules. In: Current Protocols in Immunology. John Wiley 8 Sons, New York. Vol. 2, pp A.4.1-A.4.28.

13. Civin CI, Strauss LC, Brovall C, Fackler MJ, Schwartz JF, Shaper JH. (1984) Antigenic analysis of hematopoiesis. III. A hematopoietic progenitor cell surface antigen defined by a monoclonal antibody raised against KG-la cells. J. Immunol 133: 157-165.

14. Katz FE, Tindle R, Sutherland DR, Greaves MF. (1985) Identification of a membrane glycoprotein associated with hematopoietic progenitor cells. Leukemia Res. 9: 191-198.

15. Andres RG, Singer JW, Bernstein ID. (1986) Monoclonal antibody $12-8$ recognizes a $115-\mathrm{kD}$ molecular present on body unipotent and multipotent hematopoietic colony forming cells and their precursors. Blood 67: 842-845.

16. Brown J, Greaves MF, Molgaard HV. (1991) The gene encoding the stem cell antigen, CD34, is conserved in mouse and expressed in hematopoietic progenitor cell lines, brain, and embryonic fibroblasts. Int. Immunol. 3: 175-184

17. Fina L, Molgaard HV, Robertson D, Bradley NJ, Monaghan P, Delia D, Sutherland DR, Baker MA, Greaves MF. (1990) Expression of the CD34 gene in vascular endothelial cells. Blood 75: 2417-2426.

18. Golde DW, Hocking WG, Quan SG, Sparkes RS, Gale RP. (1980) Origin of human bone marrow fibroblasts. Brit. J. Hematol. 44: 183187.

19. Berenson RJ, Andrews RG, Bensinger WI, Kalamasz D, Knitter G, Buckner CD, Bernstein ID. (1988) Antigen CD34+ marrow cells engraft lethally irradiated baboons. $J$. Clin. Invest. 81: 951-955.

20. Whalen GF, Zetter BR. Angiogenesis. In: Cohen IK, Diegelmann RF, Lindblad WJ (eds). Wound Healing: Biochemical and Clinical Aspects. WB Saunders, New York, pp. 77-95.

21. Torry DJ, Richards CD, Podor TJ, Gauldie J. (1994) Anchorage-independent colony growth of pulmonary fibroblasts derived from fibrotic human lung tissue. J. Clin. Invest. 93: 1525-1532.

22. Ross R. (1986) The pathogenesis of athero sclerosis. An update. N. Eng. J. Med. 314: 488-500.

23. Steffes MW, Mauer SM. (1990) Pathophysiology of renal complications. In: Rifkin $\mathrm{H}$, Porte D (eds). Diabetes Mellitus: Theory and Practice. Elsevier, New York, pp. 257-263.

24. Bucala R, Ritchlin C, Winchester R, Cerami A. (1991) Constitutive production of inflammatory and mitogenic cytokines by rheumatoid synovial fibroblasts. J. Exp. Med. 173: 569-574. 